\title{
ON NEW OPPORTUNITIES AND PROSPECTS OF DEVELOPMENT OF PROJECTIVE STUDY
}

\begin{abstract}
Nataliya S. Burlakova
Lomonosov Moscow State University

Moscow

The article is focused on history and logic of the evolution of projective techniques, as well as methodological problems concerning the arrangement of a study based on application of projective methods, and the analysis of the data obtained. A critical review is undertaken of the "classical" habit of thought regarding projective methods, and a new, "non-classical" approach is suggested. To lay a foundation for the suggested new approach there has been undertaken a research into peculiarities of a projective study implementation (with the CAT ${ }^{1}$ method being employed) with further consideration of the results on the material of a child development.

Keywords: history and logic of development of projective techniques, "non-classical" habit of thought concerning projective methods, exteriorization, the CAT method, assistance in self-expression.
\end{abstract}

According to L. Abt, projective technique was initially a "mutiny", a "rebel" against what was regarded as traditional, sober psychology. It acquired the impetus for cognition and understanding of an object as a whole, rejecting the very "compartmentalization" of research (that is, a separate study of his memory, or his reaction on conflicts, etc.). Academic world would take projective methods not without suspicion. G. Allport was most slashing in pointing that the interest to projective data betrays a freewheeling attitude to the very scientific character. His expostulation in "subjectivity", when personal biases of a scientist dominate in the processing of acquired results, still appeals to many opponents of the technique.

But science is a newly discovered path in getting empirical experience, if one is to compare it with other ways suggested by the culture. The science itself admits rival trends and approaches. Means and devices

1 A Child Apperception Test (S. and L. Bellak). 
providing the interconnection between theory and practice suggest yet another problem of particular importance. There is a well-shared opinion that any psychological fundamentals will rest on a certain psychotechnical pattern of production and reproduction of the experience. In this sense "psychics theory" comes as nothing but a transformed, rationally treated form representing a certain type of empirical experience in culture. To take a few examples, one may say that a psychotechnical system of activity would make a foundation for the psychological theory of activity, while a psychotechnical system of self-consciousness would underpin the psychoanalysis theory. Similar patterns and schemes define the character of experience, as well as the type of acquired knowledge (Oleshkevich, 2002).

The upshot is that the problem of the "scientific character" nowadays has become more intricate than it used to be in methodology of positivism. The "scientific character" is defined not only by the possibility of reproduction of a certain experience, but also by a specific character of interplay of the research worker and his object. K.G. Jung (1992) was suggesting in his late works that only physicists had so far arrived at this understanding. Even in physics it should seem highly improbable to exactly reproduce the same experiment, the scientists would except it and take into account the subjective element, making an "allowance for the tool". Whether the knowledge obtained through projective techniques should be vouchsafed a "scientific character" - the problem has been widely discussed (Leontyev, 1998; Sokolova, 1980, 1995; Blatt, 1975; Corman, 1974; Cramer, 1991; Handbook..., 1965; Abt \& Bellak, 1950; Rabin, 1986, etc.), but still is open to a dispute.

The present article will focus on methodological reflection over projective methods in the context of "classical" and "non-classical" scientific rationality. Taking a view of history and logic of the evolution of these methods and their strained relations with the classical scientific line of research, we shall endeavour a "non-classical" approach to projective study, taking the latter as a specific type of the specially organized interplay. In this connection we shall analyze dialogue conditions suggested for the process (employing the material obtained through the CAT method of working with children). We shall also dwell on the problem of exteriorization of the intrinsic experience, and expose the consequences of the suggested approach regarding reflexive line of the study and the work with projective materials. 


\section{History and Logic of the Evolution of Projective Techniques}

1. Traditionally projective technique was closely associated with the ideas of psychoanalytical practice. But in due course, gradually departing from clinical and psychotherapeutic sources, it has transformed into a separate, rationally arrayed psychodiagnostic procedure. It would originally play the function of reflection, at least for the initial diagnostic stage of psychoanalytical practice, and facilitate the understanding, if still unshaped and mostly intuitive, which comes to surface during the very process of treatment; it would also provide a form for its scientific verification. Today we may see the train of practices "set backwards" to psychotherapy - the practices, polished and refined in scientific research. This is manifested in the use of projective methods (with the store of knowledge on personality) as a reflected diagnostic means within the framework of psychotherapeutic treatment, and sometimes even as a separate stage of the process. (L. Bellak, E.T. Sokolova, and others). Inter alia, taking the projection in childhood comes as one of the basic therapeutic lines adopted in a number of schools. (M. Klein, D. Winnicott, alios).

2. Thematically the history of projective technique also comes in tune with that of psychoanalysis. Here the two points are important. A first comes with the fact, that C. Morgan and H. Murray, who introduced the TAT in 1935, originally regarded their method as an alternative to an expensive and time consuming psychoanalytical process, which was even more so for the young. They argued that the analysis of the projective output would come, in a way, as psychoanalysis "in miniature", especially for young people (Bellak \& Abrams, 1997). Hence, it was implicitly suggested, that the TAT method encapsulated conceptualization, accurate description, and modeling of certain essential aspects of psychotherapy, which, piled together, would make it possible to cut short the term of treatment. A second point makes obvious a gradual shift of accents in the interpretation of obtained projective data, which corresponds to different stages of the development of knowledge in psychoanalysis. It is but vividly demonstrated by the whole history of employment of projective methods. It is essential to emphasize, that transformation of manners and modes of the analysis of projective material (involving a respective "reinterpretation" of the data) becomes possible due to the fact, that psy- 
choanalytical concept which gave way to first indirect methods in studying personality, regarded its development as a succession of problemsituations, one after another solved by the individual.

2.1. In 1940-50 (when the TAT used to be widely utilized) fantasies shaped in the form of a picture-based story were interpreted mostly from the point of view of sexual and aggressive impulses in accordance with the libido theory introduced by Sigmund Freud. The TAT, as its authors believed, would help penetrate into the unconscious depths of psychic. Hence, the stories extracted by such methods would as well require the principles of dream work analysis. While within the framework of therapy such analysis was employed with the help of the patient, the processing of the TAT-developed stories suggested the use of best practice schemes of interpretation, excluding psychoanalysis from the equation. For example, the façade of obsessional neurosis is well-known to hide away a certain unconscious repression. The once noticed regularity first comes to be used in psychotherapy as such (Freud, 1999b), and then it appears as well in the interpretation of projective material (conception of the "direct penetration" into obtained material, i.e. the analysis by the scheme: "if something appears, it means..."). It triggers the idea to make use of diagnostic patterns in the analysis of projective material.

Many authors in search of a symbolic meaning of the stories and their interconnection would admit reflection of the principles of dream work analysis in psychotherapy. H. Murray would insist upon the fact when he set out to work on the stories obtained with the TAT, the rules of analysis suggested by C. Piotrowski and (if partly) L. Bellak's approach just echo the idea.

2.2. 1950 - 1970 are distinguished by generalization of the experience of European, and particularly American practice in psychoanalysis, arranged in the line of ego-psychology (A. Freud, H. Hartmann, D. Rapaport, and others), which shifted the accent on Ego and its functions. Patterns of analysis of projective material would be filled with different ways and methods of measurement of the power and adaptability of Ego, its functions, the nature of anxieties and significant conflicts, the character of defensive mechanisms, the search for estimation of interplay of Ego, Superego and Id. (Bellak, 1970; Blum, 1964; Stolorow, 1973, and others). The interest is excited towards a correlation "need/social pressure" (H. Murray). 
2.3. 1980-1990s were saturated with the interest towards the maturity of Ego and object relations. It was the period abound with efforts at integration of Ego-psychology into the theory of object relations, and correlation of the latter with J. Piaget notion of cognitive development, as well as the theory of family systems. At that time there appeared new patterns of processing projective material, which could help estimate the "motivation of intimacy", "intricacy and complexity of representations of Ego and an object", "capacity for emotional investments into relations, values and moral standards", etc. (Blatt et al., 1976; Loevinger \& Wessler, 1970; Westen, 1991; Westen et al., 1990; and others), as well as communication style within married couples, children-parental dyads. On the whole, one should say, all the attempts at integration, if significant in conception, are not particularly successful. This admits the following explanation. One should distinguish the psychoanalytic experience of Freud and experience of Piaget, since they are particularly different. Therefore, it is hardly possible to configure them on one theoretical level. Very much the same may be said about other types of experience, which integration still preserves a grave methodological problem. The marriage between Piaget theory of cognitive development and the theory of object relations, despite all efforts, will be nothing but formal. In practice relations between these two systems of analysis are much more intricate. Our own research has revealed that reversibility may already appear with a child of 4-5, though not on cognitive but on emotional level. On cognitive level it may emerge much later (Burlakova \& Oleshkevich, 2001).

3. Analysis of the evolution of projective techniques suggests a number of positive and negative aspects of development.

3.1. Among positive aspects we should name a striving for rational transparency in attaining one's knowledge of an individual in psychotherapy. It has become possible due to the creation of special, "artificial" conditions, which should expose the knowledge and relevant means of its processing. There should be marked as important the creation of "artificial", and rather short (as opposed to a long-run "natural" psychotherapeutic process) acquisition of diagnostic knowledge of deep structure of personality, which is to be further interpreted in accordance with the established framework. The pattern adopted for analysis of projective material, along with replicable habits of such assessment, is exceedingly relevant for the purposes of clinical psychology, since it reveals the knowledge accumulated in the field of psychotherapeutic practice (which 
is focused on an individual case), and gives an opportunity to extract it quick and "clear". Therefore, clinical psychology is attracted by the depth of acquired knowledge and its association with psychotherapy.

The problem of attaining rational transparency in acquired knowledge has been traditionally solved through placing a projective situation and ways of analysis among different types of classical scientific rationality: as a rule, it has been brought to a behavioristic pattern "stimulusresponse", or neo-behavioristic pattern "stimulus-organism (cognitive systems and other interpreting elements) - response". Endeavours to describe discoveries in psychoanalysis with the academese register were initiated by the research work of D. Rapaport, who was striving to turn psychoanalysis into "general psychology". Methodologists of projective psychology, in their efforts to adjust to a dominating design of scientific research, would seek the ways to prove the importance of facts attained through projective methods. More often than not they brought into play the following strategy: discoveries, retaining their psychoanalytical content, should acquire a scientese form (the latter was usually borrowed from the prevailing positivist conception of behaviorism and neo-behaviorism). The moulding into a "scientific form" is mainly responsible for infatuation with formal indices in the prejudice of content analysis of the material, which lead to a formal use of projective techniques, as a mere instrument for verification of hypotheses. This can be traced in many a present-day studies.

It has been much achieved in "thematic" development of the analysis schemes of projective material: the analysis has acquired features of a more rational clearance. But in the field of consciousness of the situation of projective study (with the exception of the most generalizing preliminary aspects) achievements have been rather modest: sacrificed to a pseudo-scientific character, the very situation was taken out of the processing to be never subjected to analysis. Designers of projective techniques would strive to make the situation to which the method is applicable as much "objective" as possible, but despite their efforts, it has been discovered that the personality of diagnostician would have a bearing on the process (Bellak \& Abrams, 1997; Kornadt \& Zumkley, 1982). Among other things, it was demonstrated, the collection of projective data may be effected by age, sex, a general emotional state (taking a form of anxiety or hostility), and even pregnancy of a diagnostician. A fractional "indirect" analysis of a projective situation was undertaken 
through the study of interaction of participants in a "conjoint TAT" or an "inter-pair Rorschach Test", transactions were regarded in married couples, as well as in child-parental pairs (Sokolova, 1985, 1987; Singer \& Wynne, 1966; Winter \& Ferreira, 1969; and others). Spontaneous emotional reactions of a researcher upon the procedure, the so called counter-transferent feelings, that emerge as a response for various metacommunicational messages implied by a projective text of a patient, have also been considered (Sokolova \& Chechelnitskaya, 1997; Kwawer et al., 1980 ). But the question is whether we can subject to reflection the very situation of a projective study in a more accurate and direct way, that is, through the unfolding relations between researcher and patient? A largescale analysis embracing the situation would fall into a "neo-classical" pattern of scientific study.

3.2. The negative aspects, in the context of correlation between psychological practice and the conceptual framework of academic psychology, appear to be the following. On the level of theory there has been reached no clear and uncontroversial understanding of what a projection is (many authors would mark the fact: Rapaport, Gill, \& Schafer, 1945-1946). The very generic diversity of projective methods "breeds" various forms, into which projective material is "encapsulated" (it is no coincidence, that we speak of structural methods, content-interpretative methods, etc.) Another problem is to attain a consistent intercropping of data, often processed out of conflicting theoretical premises.

Furthermore, as it is revealed by a review of contemporary works on clinical psychology, in most cases the application of projective techniques brings nothing new into the art of psychology, it merely verifies the "discoveries" made by psychoanalysis. Projective methods are activated mainly in the framework of those ontologistic matrices, set by psychoanalysis and its further model types, in spite of the fact that there exist other types of interpretations for projective contents, to the extent of behavioristic ones. Indeed, the TAT, for example, was not designed to reach some new scientific breaks through, it was originally meant for a technical function, to serve as a psycho-diagnostical tool, though quite novel, aimed at understanding of the integrity of a personality, or peculiarities in the development of an individual, etc. This appears to be one of the reasons to stand for the fact that projective techniques were not developed as something independent and inherently worthy. All said above does not annul the virtue of psychoanalysis, though it is still be- 
ing frowned at in the academic world, which is still inclined to forget that this very field of specific practices did harvest the phenomena and hypotheses further "reaped" by projective methods, not to name other spheres. Plenty of statistic studies do not work to extend projective technique, they might, at best, reveal some "individual distinctions"2, but not the individuality, unique and singular. Yet it was the study of individuality, recognition of "personality as a whole object", which was initially regarded as trend and perspective of projective methodology.

One may say that projective techniques (both in methods of application and in the processing of obtained material) employ mostly the ontology of psychoanalysis, but not its method, which suggests coherence of psychic contents, their correlation interdependency and comprehension of different components of psychic through one another. Instead of a conscious effort to employ the very essence of psychoanalytical method in projective techniques, what is often implied is a search for certain algorithms, clichés, etc. If we use a hermeneutic phrasing, to exclusively use the ontology of psychoanalysis would mean to sacrifice "openness" of understanding and unbound approach to material, since diagnostic judgments, more often than not, would be conditioned by schemes and patterns of interpretation or theoretical precepts of the researcher, inexplicitly striving to verify them.

In consideration of projective methods, a question inevitably arises, whether one can use them single-handedly, that is irrespectively of any theoretical patterns, to study personality on a profound level? Can we possibly adopt an unbiased and objective approach to the material on the ground of more extended and enriched analytical concepts, as, for example, dialogue approach, which suggests the concept of dialogue, providing a form of analysis, a form of acquiring knowledge, but not imposing content aspects (Burlakova \& Oleshkevich, 2001).

We believe that today the time is ripe for serious reflection over projective methodology, the structure of methods, typologization of proce-

2 For example, D.Westen together with his colleagues (Westen, Feit, \& Zittel, 1999) define projective technique as a method engaged to study individual distinctions among normal and pathological persons, which helps interpret explicit patterns of thinking, motivations or emotions exhibited in verbal habits or as a response for a standard stimulus, and implicit processes, which lie beyond the conscious introspection. The authors as well insist on application of psychometric strategies, developed on test methods, within projective techniques. 
dures, inspection of methodical material "all the way down", that is, we start with the very core of the method and proceed with consideration of certain separate techniques. Our previous work (Ibid.) sought to answer a number of questions: how the method works, how we can define the projection from a methodical point of view, how one can secure relevant informative statements. This, we assert, is much more important than any attempts to underpin projective techniques by a personality theory or a mode of analysis. We believe this approach should not only encourage profound reflection over projective methodology, but helps go beyond the originally established rule of non-involvement with the material obtained, the "outness" of psychologist, which should open further opportunities to more extended diagnostics.

\section{"Non-classical" dialogue approach to projective study}

A classical "naïve naturalism" usually dominates in projective methods. It tells itself in the fact that both the context and conditions of getting projective material are regarded as "standard" and cast aside, while the object producing the material is regarded as a "day-dreamer", "naturally projecting", producing but "crude" text. In contrast, we assume, projective study (PS) comes as a specially organized interplay, which should realize the function of actualization of intrinsic experience and involve, passively or actively, the researcher as well. That is to say, we consider the process of communication, organized with a special purpose, and reflection over those interlocutory and social conditions under which the process is taking place.

In a conducted series of experiments we have managed to prove that projective material (its expression) is always organized $a b$ extra, it is conditioned by the form suggested for its expression, among others - positions and forms of self-expression, which in part may already be planted in the consciousness of individual. The quality of obtained material, as well as the extension of conducted analysis, heavily depends on the ability of the psychologist to perceive these positions and forms of self-expressions and include them into PS. This approach brings into particular (dialogue) consideration the criteria and conditions, which constitute the very organization and functioning of the method (pressure removal, 
completeness of projective material, ambiguity, and the like); it will also encourage reflection over the interaction between the patient and the analyst (Burlakova \& Oleshkevich, 2001).

\section{Projective study of a child as a clue to reserved potential of projective technique}

When psychoanalysis once turned to treatment of a child, it disclosed the essential fundamentals of psychotherapy, which have become the part and parcel of its present-day practices (Freud, 1999a; see also: Burlakova \& Oleshkevich, 2001, 2005). Analysis of PS arrangement for children may appear very informative when we consider the content usually overlooked in treatment of grown up people, the material obtained may emphasize the importance of interplay character, as well as functioning of projective attitudes; it may help surface a number of essential problems and give ways to their solution. This may concern, for example, such criteria for organization of extrinsic dialogue as analyst's authority and its variation adjusting to child individuality, and "pressure removal." The latter is specified by the fact that in certain cases the pressure is not supposed to be removed, but is to be organized in a way to stimulate self-expression and make it feel secure, besides, the methods of pressure removal are specifically different for a child of 3 and 7.

On child material one may uncover the actual and "folded" process of the development of self-consciousness ${ }^{3}$. The original conception of the authors of TAT and CAT would objectify development, first and foremost, through the subject-matter of tables, i.e. synchronically, as for genetic analysis, it was carried out through interpretation, or injection of a certain amount of theoretical guess-work, but not through direct analysis of projective material. In PS arrangement we describe, the hermeneutic analysis of a projective text will crystallize the entire history of selfconsciousness, and the mechanisms of its functioning and reproduction, it will also display the "zone of proximal development", conditioned by the character of synthesis of intrinsic experience.

Regarding the accumulated experience in application of projective technique with CAT, we have introduced a five-level model of the analyst

3 Under the term 'self-consciousness' we assume here the structure of conscious and unconscious identifications, which form various types of inner dialogues. 
activity, which comes useful if a child's story is poor, or, unfolding it, the child encounters serious and, it would seem, insurmountable difficulties.

This mode of a kind of a "dosing assistance in self-expression" may suggest an analogy with psychotherapeutic method of the analysis of resistance, though we cannot speak of the full extent analysis of resistance within PS, we refer to an attempt to ease off the pressure, vary the researcher's attitude, in certain cases, to adjust to expectative resistance. Conflicts and opposition are presented in the projective text, as well as in the external dialogue. As it was expressed by M.M. Bahtin (1979; Voloshinov, 1993), opposition, counterwork, in a broad sense of the word, is first and foremost a form of resistance to the Other. Incorporating the image of the Other, one may weaken the opposition.

In Russian psychology the device of "dosing assistance" would mean the introduction of artificial stimulation into an experiment, it suggests an important step in reflection, a certain way to exert control over the data. It may as well be used in pathopsychology, when we turn to study the processes of thinking, and in educational psychology, when we come to arrange orientation basis of action. Nevertheless, the very idea to assist a patient in self-expression by supplying him with the means for exteriorization of intrinsic experience has never been formulated. Such ignorance of projective methodology may be accounted for by the fact that the latter was striving to develop the analysis of a free speech, taking into consideration the specificity of the object of study. Projective methodology would focus on the results of self-expression rather than the activity; any outward assistance, which would go beyond the limits of benevolent atmosphere of the experiment, was regarded as ineffective and even obstructive (Frank, 1939; Murray, 1943; and others). Self-expression through fantasy thinking of various kinds was regarded as a natural state of self-consciousness of the object, which cannot be subjected to reflection (the so called reflection of action of "primary processes").

Each of the five distinguished levels of assistance in self-expression is endued with a special function and comprises questions which, for one thing, admit no univocal and direct character and, hence, imply widely ranged variation of child answers; besides, the structure of these questions meets specific criteria of child consciousness in different age-related periods. It should be noted that the questions appear as supplementary projective stimuli, they are abstract in character and do not enter into a conflict with the idea of ambiguity of the stimulus in PS; on the contrary, 
they help specify the very character of the ambiguity which should be adopted for children of a certain age.

An essential peculiarity of the model is that it introduces the reflection of attitudes of the observer. Each of them implies a different measure of identification and dis-identification of the experimenter with a given reality of a child's story: we start with a complete identification and proceed through different variants of shifting of the listener's view from an inner attitude of the child towards an altogether outwardly, external position. The latter, chosen by the listener, permits him /her to encourage a problematic attitude, if necessary, or to attempt a random "flash-back" of the once projected material as a secondary stimulus for projection. Such method is deliberately used by the researcher to assist in self-expression, at the same time it comes as an informal diagnostic means, suggesting an opportunity to estimate on genetic and actual level the experience of Self - the Other relations. This makes particularly important the dynamics of the image of a "desired" listener in the process of story-telling (for example, making up a story in response to a certain CAT picture, a child may expect applause, or seek for support, or anticipate a trick, devaluation, deprecation, etc.). The represented dynamics may reveal the style of family communication, the particulars in reaction of "significant others", and a special nature of child's inner life.

This context will make significant not only the obtained projective material, but also the way it has been acquired. The analysis of both factors permits to verify the data, and reveals different levels of the dialogue Self-the Other. The approach, derived from the suggested basis, is characterized by a fundamentally changed methodological position: it implies rejection of a static model in favour of a developing one, and substitution of a dialogue for monologic processing of the material, which is the core of a "non-classical" version of the scientific study.

\section{The problem of exteriorization of intrinsic experience in PS}

When you come to analyze the CAT projective material, an important regularity in child development becomes evident. As the child grows older spontaneous perception of stimulus material (in the first place, its physical characteristics and relations) is replaced by the one socially-related. To take an example, responding the 2 CAT table, a three-year-old 
child will say: "these are bears", "a big bear and a bear cub"; a child of at least 4,5 will obviously map the introjected situation of his family life into the same picture: "These are mother, father and their son". But we have discovered the fact that, being addressed with a specifying question (after a freely-made story), a three-year-old child reveals a similarly structured perception. Thus, an abstract question: "Who are these bears?" usually brings the following answer: "Mother, father and their son (daughter)". Otherwise stated, if social structure does not tell itself freely and directly in the perception at an early pre-school age, this does not necessarily mean that it is not at all developed. It is rather concealed by the imperfection of verbal thinking and low abilities of verbal self-expression at the age in question. We may safely suggest that our questions, on the one hand, stimulate to surface inner socially-related mechanisms of perception, and set a form for the projection of a certain kind, on the other.

The fact that material obtained that way is "projective" is verified by the parallel examination of children's stories and family drawing technique, as well as by objective data on the character of family relations and specificity of relations with significant adults. The examination demonstrated that inner experience of children is rather directly imprinted on external objects, and their projective processes bear the structure of inner-dialogue, which extends and develops, in the first place, external interactions with family context. (L.S. Vygotsky, M.M. Bahtin). Here we may come in tune with the study, undertaken by G.T. Homentauskas (1987), A.I. Zaharov (1988), E.T. Sokolova (1995) and others. At the same time, the structure of projective processes is conditioned by the stage of development of the child, the character of identification and so on.

The indicated line of investigation as well embraces Vygotsky's idea of the "zone of proximal development" (1983): the child borrows from the adult social means of action, which, further adopted, suggest the framework for intellectual development. In our case the questions come as the means that helps a child draw outside the inner experience. That is how we get admission to it and create conditions for systematic expression of child experience. This is also regarded as the zone of proximal development.

One cannot help mentioning Freud's idea of early development of some general, basic structures of personality (consciousness). It can be called the "zone of future development" in a sense that early interactions 
of child in the family will have formed a basic personality structure by the age of 5 , the structure, which will only develop afterwards. We also believe that a child emotionally understands and experiences everything that happens to him, he is just to be assisted in his effort to form and express (exteriorize) it. This becomes possible, if we have a proper question and an attentive listener.

The two ideas described in previous paragraphs both come true, except that they belong to different levels of development and different ways of its description (Vygotsky described it from outside, as Freud from within). Freud was interested mostly in emotional, as Vygotsky - in intellectual development and the whole process of mediation of direct experience through signs. As for our work, we suggest to employ both ideas in one study and combine two levels of experience (direct, emotional-personal and rational, intellectual) within the framework of one ontology.

It is essential, that a purely methodical point of you we are striving to combine Vygotsky's ideas and concepts of psychoanalysis within the CAT techniques. When we create certain forms and constructions for self-expression and, thus, help a child to express his/her experience, we develop Vygotsky's ideas in the context of exteriorization. On the other hand, when we explore the emotional component of self-expression (through a special "intonational dialogue", which bears the experience of relations, not actual facts, "intonational echolalia", and the like), we use the method of actualization of emotional-personal level of experience, which comes close to psychoanalytical approach.

A child owes his ability for exteriorization to customary, deeply entrenched situations of communication with an adult; they imply certain expectations of child statements and necessity to bring the inner experience outside. Moreover, these situations of communication and expectancy are being raised one over the other reflecting both, a social situation of child's development and child's own attitude to the situation. But at the same time, these standard situations do not happen to cover all child abilities for self-expression. It becomes fairly obvious if we establish a more spontaneous communication, posing questions that correlate with a proper level of contact, removing "internal and external" pressure, and actualizing a new image of interlocutor. All this put together does not only permit to achieve new diagnostic material, to create new forms of self-expression, but also to trace back the whole way of 
development. This makes our work different from the line established by Vygotsky, since in our case development is organized and controlled not from the outside (i.e. through assignment of suggested patterns of activity), but from within - through exteriorization of the contents of consciousness, the structure of identifications, and through recognition of wider patterns of communication. We echo Vygotsky's approach in that we also recognize the role of signs in development, though we differ in understanding of signs in question: we believe them to be mostly derived from intrinsic experience of the child himself. By means of supportive forms of exteriorization, suggested by an adult, the child himself brings his inner signs outwards, and only after that the adult may employ these "signs" (structures of intrinsic experience) for a new wind of exteriorization, encouraging new ways and forms of child communication. In this case we follow Vygotsky's aim (though in a different way) - the aim of mastering one's own psychics through direct knowledge of the tendencies in emotional development of a child.

\section{Conclusion}

The processes of projection of intrinsic experience (interactive in its nature) with children are derived from a social situation or social context of its acquisition. Hence, it is possible to arrange the context in a way to achieve the most exhaustive form of child self-expression. This is the way to further work with the obtained projective material. Traditionally a psychologist would acknowledge a certain actual level of development of ego-functions, object relations, complexity of representations of people and the like, the non-classical approach data are taken in dynamic processing, in their formation and development, as various dialogues "Self - the Other", suggested on each level of the acquired text. There arises an opportunity to study a pathology structure in the unfolding context of the history and dynamics of the patient's intrinsic life. The classical way of processing projective material suggests either reading into a symbolic connotation with its further interpretation, or the scaling and logicalcategorical analysis of the material, which is also subjected to further interpretation. Contrary to this classical approach, we suggest to abandon explanation as an "activity of interpretation".

In such a case objectivity of researcher's conclusions will be governed, first and foremost, by language functioning, which, implicitly and 
explicitly, contain the dialogue reality of self-consciousness. A statement will appear as a unit for such an analysis. We follow M.M. Bahtin (1979) in his definition of a statement as a certain expression of self-consciousness, which functions in principle within the range of relations "Self-the Other". In the sense any statement about the Other will objectively contain a statement about the Self. When we talk about dialogue, we still bear in mind that it exceeds the language (Y.M. Lotman), so it cannot be boiled down to a speech form only.

Our approach retains all the virtues of the traditional projective study. At the same time, it strives to develop the projective techniques in the way of communication arrangement; it gives an opportunity to subject it to thorough reflection and provide a description of its conditions and parameters in the context of specific communication between the psychologist and the patient. This helps avoid unpleasant situations, when a researcher fails to obtain material, or the data appear to be exceedingly poor. The very individualization of the process suggested for the new methodology will provide the clear-cut picture of the individuality functioning and approach its delicate study. The approach provides an opportunity to study an object in his development and to witness the mechanisms of this dynamics. In this case we can get a diagnostic picture, which could point out the most important points in treatment, and to reach the inner continuity in researching procedure, the processes of diagnostics and further therapy, employing the language of both external and internal dialogue.

\section{References}

Abt, L., \& Bellak, L. (Eds.). (1950). Projective psychology. New York: Knopf.

Bahtin, M.M. (1979). Jestetika slovesnogo tvorchestva [Aesthetics of verbal creativity]. Moscow: Iskusstvo.

Bellak, L. (1970). A study of ego functions in the schizophrenic syndrome. Archives of Gen. Psychiatry, 23.

Bellak, L., \& Abrams, D. (1997). The TAT, CAT and SAT in clinical use. New York.

Blatt, S. (1975). The validity of projective techniques and their research and clinical contribution. J. of Person. Asses., 39.

Blatt, S., Brenneis, C.B., Schimek, J.G., \& Glick, M. (1976). Normal development and psychopathological impairment of the concept of the object on the Rorschach. J.of Abnorm. Psychol., 78. 
Blum, G. (1964). Defense preferences among university students in Denmark, France, Germany and Israel. J. of Project. Techn. and Person. Asses., 28.

Burlakova, N.S., \& Oleshkevich, V.I. (2001). Proektivnye metody: teorija, praktika primenenija $k$ issledovaniju lichnosti rebenka [Projective techniques: theory, practical application to the investigation of the child's personality]. Moscow: Institut obschegumanitarnyh issledovanij.

Burlakova, N.S., \& Oleshkevich, V.I. (2005). Detskij psikhoanaliz: shkola Anny Frejd [Child psychoamalysis: school of Anna Freud]. Moscow: Akademija.

Corman, L. (1974). Le test PN. Paris.

Cramer, P. (1991). The development of defense mechanisms: Theory, research, and assessment. New York.

Frank, L. (1939). Projective methods for the study of personality. J. of Psychol., 8.

Freud, A. (1999a). Vvedenie v tehniku detskogo psikhoanaliza [Introduction to the technique of child psychoanalysis]. In A. Freud, Teorija i praktika detskogo psikhoanaliza [Theory and practice of child psychoanalysis] (vol. 1, pp. 58-114). Moscow: Aprel' Press; JeKSMO-Press.

Freud, A. (1999b). Norma i patologija v detskom vozraste [Norm and pathology in childhood]. In A. Freud, Teorija i praktika detskogo psikhoanaliza [Theory and practice of child psychoanalysis] (vol. 2). Moscow: Aprel' Press; JeKSMO-Press.

Handbook of projective techniques (1965), ed. by B.I. Murstein. New York: Basic Books.

Homentauskas, G.T. (1987). Metodika «Risunok sem'i» [Draw a family test]. In A.A. Bodalev, \& V.V. Stolin, Obschaja psikhodiagnostika [General psychodiagnostics]. Moscow: Izd-vo Mosk. un-ta.

Jung, K.G. (1992). Sovremennost' i buduschee [Present and Future]. Minsk.

Kornadt, H., \& Zumkley, H. (1982). Thematische Apperzeptionsverfahren. In K.-J. Groffman, \& L. Michel (Hrsg.), Enzyklopdie der psychologie, Themenbereich B, Serie II, Bd. 3. Personlichkeitsdiagnostik (S.258-372). Göttingen: Hogrefe.

Kwawer, J., Lerner, H., Lerner, P., \& Sugarman, A. (1980). Borderline phenomena and the Rorschach test. New York.

Leontyev, D.A. (1998). Tematicheskij apperceptivnyj test [Thematic Apperception Test]. Moscow: Smysl.

Loevinger, J., \& Wessler, R. (1970). Measuring ego development: Construction and use of a Sentence Completion Test (Vol. 1). San Francisco.

Murray, H. (1943). Thematic apperception test manual. Cambridge.

Oleshkevich, V.I. (2002). Istorija psikhotehniki [History of psychotechnics]. Moscow: Akademija.

Rabin, A. (Ed.). (1986). Projective techniques for adolescent and children. New York: Springer. 
Rapaport, D., Gill, M., \& Schafer, R. (1945-1946). Diagnostic Psychological Testing (vol. 2). Chicago.

Singer, M., \& Wynne, L. (1966). Principles for scoring communication deviances in parents of schizophrenics. Psychiatry, 29.

Sokolova, E.T. (1980). Proektivnye metody issledovanija lichnosti [Projective methods of personality study]. Moscow: Izd-vo Mosk. un-ta.

Sokolova, E.T. (1985). Modifikacija testa Rorshaha dlja diagnostiki narushenij semejnogo obwenija [Modification of the Rorschach test to diagnose violations of family communication]. Voprosi Psikhologii, 4.

Sokolova, E.T. (1987). Sovmestnyj test Rorshaha dlja diagnostiki narushenij semejnogo obschenija [Joint Rorschach test for the diagnosis of family communication]. In A.A. Bodalev, \& V.V. Stolin (Eds.), Obschaja psikhodiagnostika [General psychodiagnostics]. Moscow: Izd-vo Mosk. un-ta.

Sokolova, E.T. (1995). Izuchenie lichnostnyh osobennostej i samosoznanija pri pogranichnyh lichnostnyh rasstrojstvah [The study of personality traits and self-consciousness in borderline disorders of personality]. In E.T. Sokolova, \& V.V Nikolaeva, Osobennosti lichnosti pri pogranichny rasstrojstvah i somaticheskih zabolevanijah [Personality traits in borderline disorders and somatic diseases]. Moscow: SvR-Argus.

Sokolova, E.T., \& Chechelnitskaya, E.P. (1997). O metakommunikacii v processe proektivnogo issledovanija pacientov s pogranichnymi lichnostnymi rasstrojstvami [About metacommunication in the process of projective studies of patients with borderline personality disorders]. Moskovskij psikhoterapevticheskij zhurnal, 3.

Stolorow, R. (1973). TAT coding system for the theme of voluntary control. New York.

Voloshinov, V.N. (1993). Frejdizm [Freudism]. Moscow: Labirint.

Vygotsky, L.S. (1983). Istorija razvitija VPF [History of development of HMF]. In L.S. Vygotsky, Collected works (vol. 3). Moscow: Prosveschenie.

Westen, D. (1991). Social cognition and object relations. Psychol. Bull., 109.

Westen, D., Feit, A., \& Zittel, C. (1999). Methodological issues in research using projective methods. In P.C. Kendall, J.N. Butcher, \& G. Holmbeck (Eds.), Areas of clinical research: Assessment. $2^{\text {nd }}$ ed. New York.

Westen, D., Lohr, N., Silk, K. et al. (1990). Object relations and social cognition in borderlines, major depressives, and normals: a TAT analysis. Psychol. Assessment: J. of Consul. and Clin. Psychol., 2.

Winter, W.D., \& Ferreira, A.J. (1969). Research in family interaction: Readings and commentary. Palo Alto, CA.

Zaharov, A.I. (1988). Nevrozy u detej i podrostkov [Neuroses in children and adolescents]. Leningrad: Medicina. 